\title{
O ENSINO COM A PESQUISA ENGENDRANDO A PRÁXIS DOCENTE: UM ESTUDO COM ACADÊMICOS DE PEDAGOGIA
}

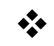 \\ Luziêt Maria Fontenele-Gomes \\ Universidade Estadual do Sudoeste da Bahia - UESB - Brasil \\ Maria de Cássia Passos Brandão Gonçalves \\ Universidade Estadual do Sudoeste da Bahia - UESB - Brasil
}

\section{Resumo}

Este trabalho tem por objetivo discutir o ensino com pesquisa na formação de professores por ser uma metodologia que possibilita o protagonismo do estudante, no qual ele é o autor e proponente do seu processo de aprendizagem. O material de análise é constituído por textos escritos produzidos pelos estudantes de Pedagogia, matriculados na disciplina Educação de Jovens e Adultos, participantes dessa experiência, composto por depoimentos dos professores e alunos da EJA da rede municipal de ensino, obtidos por meio de entrevistas semiestruturadas; registros de observações realizadas em salas de aula de EJA. Analisou-se a constituição e o desenvolvimento dessa prática, dialogando com autores como: Cunha (s.d.); Esteves (2001); Soares (2012, 2013a, 2013b) dentre outros, que, ao se debruçarem sobre a formação na universidade, têm criticado o ensino por meio da aula magistral e apresentado o ensino com pesquisa como uma das possibilidades metodológicas para a formação de um profissional mais crítico e com autonomia, capaz de tomar decisões frente às incertezas do seu campo de atuação. O ensino com pesquisa convoca os professores universitários a enfrentarem os desafios da formação em suas diversas dimensões: social, cultural e pedagógica. Essa última dimensão - a pedagógica - ao pressupor o deslocamento da docência centrada no professor para o protagonismo do estudante, busca a unicidade existente entre teoria e prática e, também, a articulação necessária entre universidade e escola.

Palavras-chave: Ensino com pesquisa. Docência universitária. Educação de jovens e adultos.

\section{Introdução}

Nos últimos anos, os professores universitários, formadores de professores, têm sido convocados a adotar práticas educativas que possibilitem ao estudante, futuro professor, um papel ativo na construção do conhecimento. O desafio de formar cidadãos e profissionais capazes de analisar a informação, interagir e assumir uma condição ética em relação ao conhecimento produzido, num contexto universitário marcado, pela democratização do acesso, oportunizando o ingresso de pessoas pertencentes a grupos sociais historicamente excluídos. E, a revolução tecnológica, trazida pelas novas formas de veiculação da informação 
e comunicação, tem acenado para a necessidade da superação de uma prática centrada no ensino que ainda hoje privilegia a aula magistral (CUNHA, s.d; POZO, 2009; SOARES, 2012, 2013a, 2013b).

No entanto, os currículos dos cursos de licenciatura padecem dos mesmos dilemas denunciados em décadas anteriores, tais como: ausência de articulação da universidade com as escolas de educação básica, campo de atuação profissional dos futuros professores; dicotomia entre teoria e prática; separação entre disciplinas pedagógicas e disciplinas de conhecimentos específicos dentre outros. Mesmo os estudos e pesquisas da área de educação, frequentemente, evidenciarem esses problemas e os estudantes dos cursos de licenciatura, ao se depararem no período do estágio com situações inesperadas e inusitadas, também manifestarem suas críticas.

Há que considerar que a necessidade de alteração nas formas de ensinar e aprender na universidade requer dos formadores de professores mudanças de concepção que exigem um apoio institucional, sobretudo, na perspectiva de uma formação pedagógica. Isso porque no Brasil a preparação para o exercício do magistério superior, segundo a LDB no 9.394/96 (BRASIL, 1996), é realizada em nível de pós-graduação, em programas de mestrado e doutorado. E, como apontam Anastasiou e Alves (2010), não há nesses programas uma preocupação com a formação pedagógica, os conhecimentos e as habilidades enfatizadas, quase sempre, são voltados para a formação do pesquisador, os aspectos relacionados ao ensino são trabalhados de forma pontual em algumas disciplinas isoladas, geralmente, de natureza optativa.

Nesse sentido, inovar nas metodologias de ensino na graduação é correr o risco de assumir o novo, é o professor se colocar também como sujeito de aprendizagem, principalmente, quando se busca uma maior integração entre ensino e pesquisa. A relação entre pesquisa e ensino não é uma relação simples e fácil de estabelecer, sobretudo quando não se têm uma formação que proporcione a "apropriação de saberes e fazeres próprios do magistério superior" (BOLZAN; ISAIA, 2010, p.16), incluindo formas de ensinar e aprender relacionadas aos adultos. Além disso, o contexto acadêmico, até mesmo a pesquisa no ensino por se aproximar da pesquisa-ação, tem ocupado um lugar marginal na maioria das instituições universitárias, visto que "em geral, não é percebida como geradora de conhecimento científico, pois, na lógica dominante, ela não garante objetividade, neutralidade do pesquisador, nem possibilidade de identificação de causas e leis mais gerais e, portanto, de generalização" (SOARES, 2014, p.94). 
Desse modo, em um trabalho que busca articular ensino e pesquisa, é necessário, portanto, diferenciar o ensino para a pesquisa ou para formação do pesquisador profissional ou acadêmico do ensino com pesquisa, ainda que não haja uma contradição entre essas duas lógicas (PAOLI, 1998). O ensino para a pesquisa é aquele desenvolvido em programas de pós-graduação strictu sensu articulado com a lógica da produção de conhecimento novo. Já o ensino com pesquisa na formação inicial de professores está voltado para o processo de aprendizagem que se constrói no movimento dialético e dialógico entre teoria e prática, por meio do desenvolvimento de uma multiplicidade de competências e atitudes necessárias a um fazer docente que, de forma comprometida e responsável, possa se efetivar em contextos diversos e incertos (SOARES, 2013a).

É necessário, também, como adverte Soares (2013a, p.218), não confundir o ensino com pesquisa com práticas que se utilizam dos resultados de pesquisas nas aulas ministradas na graduação, tampouco como uma atividade restrita à disciplina Metodologia da Pesquisa, desenvolvida de forma "prescritiva, intelectualista, que "ensina" a fazer, mas não oportuniza a experiência de fazer pesquisa". Assim, assumir o risco do novo, é investir na pesquisa, compreendendo-a como princípio formativo capaz de desenvolver atitudes científicas, o espírito crítico e a autonomia, é apostar no protagonismo e na participação ativa dos estudantes - sujeitos da aprendizagem.

Partindo desses pressupostos, pretende-se neste artigo analisar uma experiência de ensino com pesquisa desenvolvida na disciplina de Educação de Jovens e Adultos - EJA, em um Curso de Pedagogia.

\section{Apostando no ensino com pesquisa}

A proposta de ensino com pesquisa na disciplina de Educação de Jovens e Adultos se concretizou após a experiência exitosa de algumas atividades de investigação realizadas nas escolas, em turmas de EJA, em semestres anteriores e, também, a partir de um maior aprofundamento nos estudos sobre a pesquisa como princípio formativo. Desse modo, para a elaboração do plano de trabalho, tomou-se como referência além dos estudos publicados por Cunha (s.d), Esteves (2001) e Soares (2012; 2013a, 2013b), os relatos dos estudantes de semestres anteriores, que participaram de atividades de investigação na disciplina e expressaram os seus sentimentos em relação às contribuições das atividades de pesquisa em seu processo formativo. Em um dos relatórios do semestre, uma estudante manifesta os seus sentimentos em relação à atividade: 
[...] contribuiu de forma grandiosa para a nossa formação pedagógica e, principalmente, pessoal. Ampliou nossas concepções, favoreceu a visualização de uma pequena parte desse sistema educacional, proporcionando-nos o conhecimento de profissionais que se comprometem com a educação, para além da técnica de alfabetização, alcançando uma dimensão de promoção humana para o aluno da EJA e, assim, para a sociedade. (RELATÓRIO GERAL DA EJA - PEDAGOGIA, p. 21, 2015, grifo nosso)

O uso da expressão "ampliou nossas concepções" foi quase unânime pelos estudantes do Curso de Pedagogia, quando ressaltam que somente ao chegar à escola é que puderam realmente compreender do que tratavam os textos estudados em sala de aula. E, acrescentavam que "atividades como essas deveriam ser realizadas desde o início da disciplina". Outro aspecto importante a ser destacado nesse relato foi a expressão: "o conhecimento de profissionais que se comprometem com a educação", ainda que essa não tenha sido uma constatação que estivesse presente na maioria dos relatos dos estudantes. Como exemplo, destaca-se um fragmento das considerações da estudante E1, ao refletir sobre sua visita a uma turma de $1^{\text {a }}$ série da EJA:

\footnotetext{
[...] percebemos como a escrita do nome tem importância para as pessoas adultas e questionamos: será que a forma trabalhada pela professora é suficiente para garantir o trabalho? Se o aprendizado é construído, quais as estratégias devem ser utilizadas para alfabetizar pessoas adultas? Somente dizer o nome das letras é suficiente? (RELATÓRIO GERAL DA EJA - PEDAGOGIA, p. 23, 2015)
}

Tanto a expressão "o conhecimento de profissionais que se comprometem com a educação" como o relato da estudante E1 foram justificativas que, ainda de naturezas diferentes, contribuíram para que fosse elaborada a proposta de trabalho do semestre visando aproximar o estudante da escola, campo de atuação profissional do futuro professor. Vivenciar a prática em sua diversidade e em seus variados contextos é uma atividade formativa que proporciona o desenvolvimento de uma multiplicidade de competências e atitudes relacionadas à profissão de professor.

$\mathrm{O}$ exercício de questionar para buscar conhecer e compreender como se constitui o processo de alfabetização e qual(is) a(s) metodologia(s) mais adequada(s) para o ensino e a aprendizagem de pessoas adultas, fundamentados numa concepção de aprendizagem construtivista, são etapas importantes da aprendizagem da docência. Elas permitem ao futuro professor o desenvolvimento de competências capazes de responder às situações problemáticas relacionadas ao fazer docente.

Tomando o conceito de "práticas aninhadas", descrito por Sacristán (1999), pode-se afirmar que, nesse movimento de ensino com pesquisa, são oportunizadas a articulação de diferentes práticas. Práticas organizativas referentes ao funcionamento e à organização da 
escola; práticas didáticas relacionadas às concepções e às metodologias de ensino das áreas específicas do conhecimento. E, práticas concorrentes que incluem as políticas públicas de educação expressas nos livros didáticos, referenciais, diretrizes e orientações curriculares encaminhadas pelas Secretarias de Educação e/ou Ministério da Educação. Todas essas práticas se constituem como campo, por excelência, do desenvolvimento de competências da profissão docente, uma vez que inter-relacionam teoria e prática; articulam saberes, capacidades, habilidades e atitudes. Essa imersão na cultura profissional, desde a formação inicial, contribui para o processo de desenvolvimento profissional docente e do tornar-se professor. Todavia, para que esse desenvolvimento aconteça, é imprescindível que o formador de professor invista num processo formativo que proporcione a construção do pensamento compreensivo, crítico, criativo e de tomada de decisões dos estudantes. Outrossim, o planejamento de atividades que promovam a realização de inferências, análise da informação, investigação das fontes, interpretação das causas, previsão dos efeitos, estabelecimento de relações, empreendimento de metas dentre outras, que se tornam mais viáveis quando relacionadas aos problemas do contexto da profissão (LIZARRAGA, 2010; ZABALA, 2010).

De forma semelhante, as atitudes também se desenvolvem "mediante a sua aprendizagem em um contexto de interação" (TRILLO, 2000, p.222), o que se torna imperioso na atividade de ensino com pesquisa proporcionar aos estudantes uma indução na cultura escolar, bem como um trabalho colaborativo para que possam, de forma intencional e reflexiva, explicitar convicções, crenças e valores que embasam suas emoções de agrado ou desagrado em relação às situações por eles vivenciadas, a fim de serem negociadas no espaço formativo.

A análise desses relatos, aliadas aos estudos da área, ratificaram a escolha da abordagem metodológica de ensino com pesquisa. Adotar essa metodologia de ensino é oportunizar ao estudante a possibilidade de assumir "o estatuto de sujeito interativamente ativo no processo de construção do conhecimento, em que se faz indispensável o indagar para vir a conhecer" (GONÇALVES; FREIRE, 2012, p.9).

As expectativas dos estudantes matriculados na disciplina no semestre também foram importantes para o desenvolvimento da proposta. Tomar os sujeitos como protagonistas da formação requer que consideremos: seu compromisso e responsabilidade com o processo de aprendizagem, tempo, disponibilidade, autoconfiança, autoestima, capacidade de aprender, assumir riscos, socializar as experiências prévias, bem como de participar dos processos de construção e reconstrução do conhecimento (GARCIA GÓMEZ, 1999). 
Nesse sentido, os estudantes mostraram-se motivados para o trabalho, inicialmente movidos por uma "curiosidade ingênua", marcada pela história de escolarização de seus familiares, pais, avós, tios e irmãos, que se assemelham aos alunos da EJA e, também, por uma "curiosidade epistemológica" por parte de alguns que já participam de projetos de extensão na área da EJA (FREIRE, 1996).

Assim, partindo do objetivo da disciplina, compreender os fundamentos históricos, legais e pedagógicos da educação de jovens e adultos no Brasil, desenhou-se o programa do semestre que segue especificado na Figura 1, buscando problematizar as crenças dos estudantes, bem como as concepções e práticas de ensino e aprendizagem vigentes em turmas de EJA de escolas da rede municipal de ensino.

\section{Figura 1 - Desenho do Programa da disciplina Educação de Jovens e Adultos}

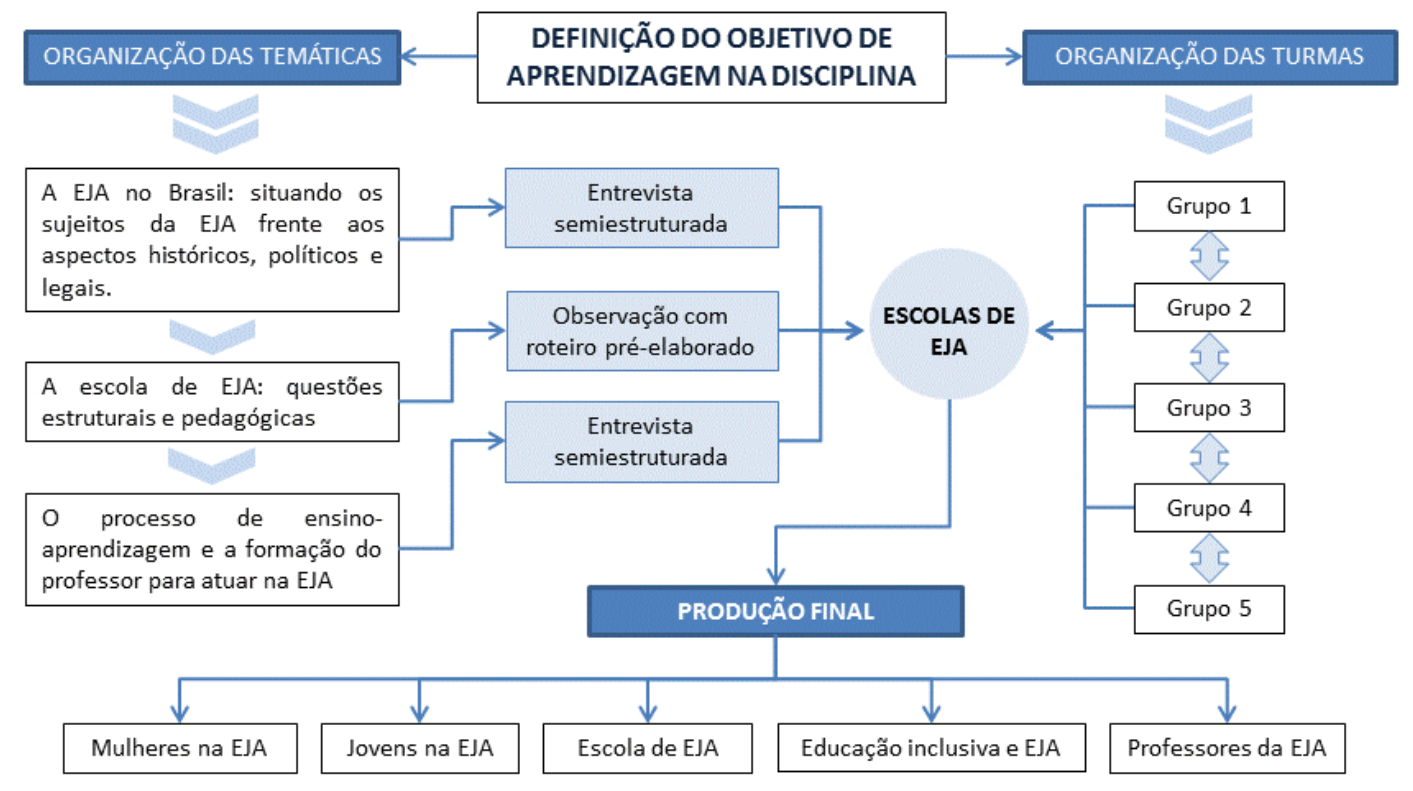

Fonte: Autoria das professoras autoras.

\section{Experiência do ensino com pesquisa no curso de Pedagogia}

O processo dialético-problematizador foi o princípio fundante de todo o trabalho, como mencionado na Figura 1, por possibilitar, através do diálogo, que se olhe o contexto e a si mesmo "como processo, algo em construção, como realidade inacabada e em constante transformação" (STRECK; REDIN; ZIRTKOSKI, 2008, p.130). Desse modo, inicialmente, foram discutidos e acordados com o grupo algumas metodologias de trabalho que privilegiam 
a participação ativa dos estudantes nas discussões e debates em sala de aula e definido o eixo temático da primeira unidade. Posteriormente, com base na ementa e também nas necessidades que iam sendo suscitadas a partir das visitas às escolas, foram sendo decididos os temas da segunda e terceira unidade. Somente ao final desse roteiro é que se construiu o mapa que ilustra a Figura 1, o que não significa afirmar que não houve um planejamento; ao contrário, o planejamento foi elaborado de forma participativa, colaborativa e em consonância com o movimento da aprendizagem, de forma a contemplar não apenas o produto, mas sobretudo o processo, visto que é ele que conduz a aprendizagem.

No movimento de idas e vindas às escolas, foram sendo construídos os dispositivos de pesquisa, ficha de observação e roteiro semiestruturado das entrevistas realizadas pelos estudantes licenciandos aos alunos e professores da EJA. Ao término de cada unidade realizava-se, inicialmente, a socialização e o debate das impressões registradas de cada grupo, identificando semelhanças e diferenças existentes entre as realidades pesquisadas. Em seguida, em dupla elaborava-se um quadro único de categorização dos achados. E, finalizando, após a análise e discussão dessas categorias, elegiam-se, em conformidade com o eixo norteador da unidade, as questões mais relevantes para um aprofundamento teórico. Os trechos das entrevistas de três alunos da EJA ilustram duas das categorias eleitas:

[...] estudei quando era pequeno, mas acho que não fui alfabetizado. (A1, 18 anos)

Então naquele tempo não existia colégio, porque se fosse como hoje que se tiver um aluno o carro tem que buscar... antigamente não existia, só quem estudava antigamente era o filho dos ricos, dos patrões, fazendeiros; agregado não estudava, não tinha... não sei, morava em uma roça que não tinha escola e ficava naquilo mesmo. (A7, 63 anos)

Ah! Tenho muito sonho, o primeiro sonho que tenho é aprender a ler para poder
escrever um diário. Eu acho lindo uma pessoa escrevendo, daí eu me sinto assim
incapaz por não saber. Quando, às vezes, vejo meu filho falando: mãe me ensina a
ler ? Me dói muito, porque como que posso ensinar, é um cego guiando outro cego
e aquilo me dói muito de ver meu filho, às vezes, me pedindo pra poder ensinar ele
na leitura e não posso, e eu peço pra ele mandar o pai dele ler, e o pai fica naquele
enrola, e dói muito porque eu tinha vontade de sentar com ele, ler uma história, ler
um tema, sinto muita vontade. Sinto vontade também de participar, tem amigo que
manda convite no facebook, mas como né? Convite é bom, mas escrever o quê?
Como eu posso falar alguma coisa se eu não sei escrever? Quando alguém fala
comigo eu tenho que esperar meu menino chegar pra ele escrever, por isso eu tenho
muita vontade de aprender a ler e escrever. (A6, 35 anos - RELATÓRIO GERAL
DA EJA - PEDAGOGIA, p. 17, 2015)

Nesta unidade, de acordo com os achados nas atividades de campo, os temas definidos foram o aprofundamento dos estudos no processo de juvenilização da EJA e o analfabetismo no Brasil envolvendo as questões do preconceito de gênero, raça, classe social e outros. A 
cada nova unidade, outras temáticas foram sendo trabalhadas, a partir dessa mesma dinâmica. Sobre esta primeira etapa do trabalho, os sentimentos de duas estudantes afirmam que:

\begin{abstract}
[...] esta é uma forma de melhoria da prática pedagógica, possibilitando assim, uma melhoria em nossa formação, uma vez que por meio do contato direto com o sujeito que compõe a Educação de Jovens e Adultos - EJA, podemos fazer uma estreita relação do fazer pedagógico. Do ideal ao real, proposto para essa modalidade de ensino. Nesse sentido, tal processo necessita de mudanças na nossa concepção de ensino e de aprendizagem, como também em nossa postura enquanto alunos em processo de formação do curso de Pedagogia e, consequentemente, futuros pedagogos. (RELATÓRIO GERAL DA EJA - PEDAGOGIA, p. 19, 2015, grifo nosso)
\end{abstract}

Essa não é uma tarefa fácil, visto que exige dos formadores de professores muito mais tempo de dedicação à disciplina, com a busca por metodologias que provoquem o grupo para a discussão, o debate, mobilizando-os a fazer leitura prévia dos textos e, primordialmente, a expressarem o que sentem em relação às atividades desenvolvidas. $\mathrm{O}$ ato de aprender inclui tanto os aspectos cognitivos, como os afetivos e de relacionamentos, como afirma Freire (1996, p.141), “afetividade não se acha excluída da cognoscibilidade”. Nesse sentido, algumas questões que se apresentam no processo como contraditórias, por exemplo, as solicitações dos alunos para que se inovem as práticas de ensino, mas ao mesmo tempo a resistência a um trabalho mais colaborativo, construtivo, justificado por falta de tempo para realização das leituras, da atividade de pesquisa e outros, por vezes, podem ser manifestações relacionadas aos aspectos afetivos, isto é, mecanismos usados inconscientemente para proteger as suas crenças (DAY, 2001).

Nessa perspectiva, a mudança contumaz se torna um desafio para o formador de professor, por exigir o deslocamento do lugar de "dar aula", de fazer "exposição do conteúdo" para tornar-se capaz de desenvolver questionamentos que provoquem desequilíbrios cognitivos e atitudinais nos estudantes, o que exige não somente o domínio de conhecimentos específicos da disciplina, mas também um maior conhecimento da cultura do aluno, das suas experiências e, consequentemente, de uma escuta sensível.

Com essa experiência, reafirma-se o pensamento de que o processo de formação não pode ser pensado numa perspectiva meramente instrumental, como um movimento de "fora para dentro", cabendo ao professor somente um domínio de uma teoria para que possa ser transmitida. Os conteúdos a serem aprendidos "contém em sua lógica interna, uma forma que lhe é própria, e que precisa ser captada e apropriada para sua efetiva compreensão" (ANASTASIOU; ALVES, 2010, p. 3). 
Assim, a organização da turma em grupos de trabalho deve ser constituída com o objetivo de proporcionar o diálogo, a troca de saberes, mas também é necessário que se cultive o momento individual de elaboração do próprio sujeito. Nesse sentido, as atividades em grupo e individual se intercalavam, de modo que a estratégia do trabalho em grupo fosse utilizada quando a interação entre os alunos se tornava o principal aporte para a compreensão, a análise, a tomada de decisão. Já que, como afirma Pozo (2009, p.68): “[...] la discusión colectiva sobre las diversas alternativas permite valorar sus ventajas e inconvenientes y construir nuevas estrategias o planes de acción integrando a las anteriores".

Pensar novas abordagens de ensino e aprendizagem requer que se pense na forma de organização da turma, em consonância com os conteúdos a serem ensinados e apreendidos. Não é simplesmente a substituição de metodologias tradicionais de ensino, mas compreender que a principal operação exercitada nessas metodologias - a memorização - tem se revelado insuficiente em um contexto marcado por grandes transformações, quer sejam epistemológicas, tecnológicas ou culturais (POZO, 2009).

\section{Processo de culminância da atividade}

Mantendo o princípio da dialogicidade proposto por Freire (1996), a qual implica numa postura de abertura ao outro, em um pensar crítico e criativo, é que na construção do "contrato didático", elaborado no início da disciplina com o grupo, ficou acordado que no decorrer das unidades, seriam eleitas as temáticas para produção de um texto final. A aproximação da universidade das escolas não deve servir só para "munir os estudantes de um arsenal de conhecimentos e técnicas" (ZEICHNER, 1983 apud ESTEVES, 2001, p.222), deve provocá-los a problematizar a realidade e, assim, irem aprendendo a analisá-la e a interpretála, elaborando, quando possível, sugestões de ações factíveis para serem desenvolvidas.

Nessa perspectiva, os estudantes ao realizarem suas escolhas para a elaboração do trabalho final da disciplina, de acordo com critérios de afinidades definidos por eles, foram se agrupando em torno de uma temática e se debruçando na análise e interpretação dos achados da pesquisa de forma mais densa e articulada com as teorias. As temáticas eleitas foram: a das mulheres na EJA e a relação com gênero; o fenômeno da juvenilização; a formação do professor; o processo de inclusão e a organização estrutural e pedagógica da escola.

Ao final da disciplina, ao apresentarem e debaterem os textos em sala de aula, foi percebido que os estudantes não mobilizaram apenas saberes, mas assumiram também a autonomia e um compromisso ético e estético com sua futura profissão. Os trechos que 
seguem, extraídos de suas reflexões finais acerca de duas das temáticas em estudo, ilustram essa percepção:

\begin{abstract}
Refletir sobre como esses jovens (referindo-se aos entrevistados) pensam e compreendem a EJA, requer de nós, pensarmos historicamente, quem são os sujeitos que ingressam na EJA; quais são suas expectativas diante do retorno à escola; que conhecimentos têm a respeito do mundo externo, sobre si mesmo e sobre as outras pessoas. Talvez, assim, não corremos o risco de defini-los por aquilo que não são e, em nome de uma educação igualitária, oferecer-lhes um ensino homogêneo que valorize determinado grupo cultural. (Grupo 2 - Os jovens da EJA: o que revelam os sujeitos)
\end{abstract}

[...] percebemos a necessidade de pesquisas mais aprofundadas nessa área, dado ao advento de pessoas com deficiência nessa modalidade. Apesar da criação das políticas de educação especial na perspectiva inclusiva datarem de 2007, as pessoas com deficiência continuam enfrentando barreiras no que concerne ao acesso e à permanência na escola. Faz-se necessário superar programas e ações isoladas, descontínuas e de cunho assistencialista, além de superar o sentimento de culpa atribuída ao aluno, usado, ainda hoje, como explicação para os insucessos e a consecutiva exclusão dos alunos deficientes das escolas. (Grupo 4 - Alunos com deficiência na EJA: uma dupla inclusão - RELATÓRIO GERAL DA EJA PEDAGOGIA, p. 21-22, 2015)

Para os estudantes, a elaboração do texto final foi a atividade mais desafiante e para os professores a que exigiu uma maior disponibilidade de tempo. Ações como mediar a construção do texto, atentar para os aspectos cognivos e emocionais, realizar questionamentos, acenar para a necessidade de uma descrição dos dados de forma mais detalhada, sistemática e articulada teoricamente. E, ainda, auxiliar nas questões relacionadas ao uso da língua padrão, visto que muitos estudantes apresentavam inúmeras dificuldades e lacunas em sua formação foram atividades que o tempo exigido ultrapassa o limite "convencional".

Os resultados finais das produções dos estudantes foram posteriormente sistematizados pelas formadoras e apresentados para os professores e alunos da EJA, participantes da atividade formativa. Em depoimento, a Coordenadora da Educação de Jovens e Adultos, da Secretaria Municipal de Educação, destacou a relevância da atividade afirmando:

[...] vejo de significativa relevância a parceria da universidade com a rede básica, principalmente quando há diálogos desta forma, cujos dados são colhidos na rede, contudo, depois apresentados e discutidos, contribuindo assim para uma ressignificação da práxis. (RELATÓRIO GERAL DA EJA - PEDAGOGIA, p. 25, 2015.1)

Os professores da rede municipal, parceiros no processo de formação, expressaram seu sentimento de pertença ao trabalho. A fala de uma das professoras ilustra esse sentimento: "Esse é um momento ímpar. Sentimo-nos valorizadas, reconhecidas quando somos chamadas 
para essa reflexão" (RELATÓRIO, p. 26, 2015). Alguns estudantes, ao final da disciplina, relatam que:

Foi importante também para nossa formação enquanto futuras pedagogas, pois até
então não tínhamos vivenciado uma experiência de ensino como essa, e por esse
motivo nos possibilitou adquirir um novo olhar sobre a área de atuação profissional
do professor e sua importância no auxílio à formação de cidadãos críticos e
participativos na sociedade em que vivem.
[...] obtivemos experiências significativas para a nossa formação enquanto futuras
pedagogas, pois contribuiu para a reflexão acerca do ensino.
[...] percebemos o quão gratificante foi esta experiência na escola, pois nos permitiu
sair da teoria e vivenciar um pouco da realidade, além de nos ajudar na construção
de novos conhecimentos e de uma visão diferenciada a respeito do ensino.
(RELATÓRIO GERAL DA EJA - PEDAGOGIA, p. 23,2015 , grifo nosso)

Os professores universitários, ao se constituirem como formadores de professores "aventureiros", compartilham também o sentimento dos estudantes quando afirmam que "foram experiências significativas para a nossa formação" (RELATÓRIO, p. 27, 2015). E, assim, reconhece-se a necessidade de um contínuo investimento nos estudos e na construção de novas abordagens de ensino e aprendizagem na universidade. A afirmação "nos permitiu sair da teoria" provoca a todos novas reflexões.

\section{Considerações finais}

A prática do ensino com pesquisa engendrando a práxis docente exige dos formadores uma compreensão maior sobre o processo de aprendizagem do adulto, para que possam pensar estratégias de atividades que realmente possibilitam provocar os estudantes, mobilizálos para a construção do conhecimento, considerando a tradição de um processo de ensinoaprendizagem referenciado na memorização e no recebimento passivo da informação.

No contexto da formação de futuros professores, a pesquisa como eixo da formação, assume o sentido cunhado por Freire (1996, p. 27), da “corporeificação das palavras”. É viver na sala de aula da graduação, a experiência da unidade entre teoria e prática, da dialética, da troca, do diálogo, expressões tão propaladas no discurso que a universidade assume perante a educação básica, ao orientar que seus projetos educativos sejam fundamentados em uma concepção de aprendizagem construtivista.

Assim, acredita-se que revisitar a prática na busca por teorizá-la se constitui em uma importante atividade formativa na qual se pode analisar e compreender os acontecimentos, desvelando as teorias implícitas presentes na ação pedagógica. Juntamente com Soares (2013), pode-se afirmar que a pesquisa como princípio formativo envolve uma ressignificação 
da concepção de ensino e de aprendizagem, não somente de estudantes, mas também dos professores universitários.

\title{
TEACHING WITH RESEARCH ENGENDERING PRAXIS FACULTY: A STUDY WITH PEDAGOGY STUDENTS
}

\begin{abstract}
This work aims to discuss the teaching with research in teacher education to be a methodology that enables the student role, in which he is the author and proponent of the learning process. This work aims to discuss the teaching with research in teacher education to be a methodology that enables the student role, in which he is the author and proponent of the learning process. The analysis material consists of written texts produced by Pedagogy students enrolled in adult education course, participants of this experience, composed of testimonies of teachers and students of the EJA of municipal schools, obtained through semistructured interviews ; observations records held in classrooms EJA. We analyzed the constitution and the development of this practice, dialoguing with authors such as: Cunha (s.d.); Esteves (2001); Soares (2012, 2013a, 2013b) among others, which, to pore over the training at the university, have criticized teaching through the master class and presented the teaching with research as one of the methodological possibilities for the formation of a more critical professional and autonomous, able to take decisions facing the uncertainties of their field. The teaching with research calls on academics to face the challenges of education in its various dimensions: social, cultural and educational. This latter dimension - pedagogical - to assume the displacement of teaching centered on the teacher to the student role, search the existing unity between theory and practice and also appropriate relations between university and school.
\end{abstract}

Keywords: Teaching with research. University teaching. Education of youth and adults.

\section{DOCENCIA COM LA INVESTIGACIÓN COM LA ENGENDRAMIENTO DE LA PRAXIS DOCENTE: UN ESTUDIO CON ACADÉMICOS DE PEDAGOGÍA}

\section{Resumen}

Este trabajo tiene como objetivo discutir la enseñanza con la investigación en la formación del profesorado a ser una metodología que permite que el papel de los estudiantes, en la que él es el autor y promotor del proceso de aprendizaje. El material consiste en el análisis de textos escritos producidos por los estudiantes de Pedagogía matriculados en el curso de educación de adultos, los participantes de esta experiencia, compuesto por testimonios de profesores y estudiantes de la EJA de las escuelas municipales, obtenidos a través de entrevistas semiestructuradas; registros de las observaciones realizadas en las aulas de educación de adultos. Hemos analizado la constitución y el desarrollo de esta práctica, en diálogo con autores como: Cunha (S. D.); Esteves (2001); Soares (2012, 2013th, 2013b), entre otros, los cuales, a lo largo de los poros de la formación en la universidad, han criticado la enseñanza a través de la clase magistral y presentó la enseñanza con la investigación como una de las posibilidades metodológicas para la formación de un profesional más crítica y autónomo, capaz de tomar decisiones frente a la incertidumbre de su campo. La enseñanza con la investigación hace un llamamiento a los académicos para hacer frente a los retos de la educación en sus diversas dimensiones: sociales, culturales y educativas. Esta última dimensión - pedagógica - asuma el desplazamiento de la enseñanza centrada en el profesor al 
papel del estudiante, buscar la unidad que existe entre la teoría y la práctica y las relaciones también apropiados entre la universidad y la escuela.

Palabras clave: Enseñanza con la investigación. La enseñanza universitaria. La educación de jóvenes y adultos.

\section{Referências}

ANASTASIOU, Léa das Graças Camargo; ALVES, Leonir Pessate (Orgs.). Processos de ensinagem na universidade. Pressupostos para as estratégias de trabalho em aula. 7. ed. Joinville: Ed. da UNIVILLE, 2010.

BOLZAN, Doris Pires Vargas; ISAIA, Silvia Maria de Aguiar. Pedagogia universitária e aprendizagem docente: relações e novos sentidos da professoralidade. Revista Diálogo Educacional, Curitiba, v.10, n.29, 2010.

BRASIL. Presidência da República. Lei 9.394, de 20 de dezembro de 1996: estabelece as diretrizes e bases da educação nacional. Diário Oficial da União. Brasília, DF, 23 dez. 1996. Disponível em: <http://www.planalto.gov.br/ccivil_03/leis/L9394.htm>. Acesso em 30 abr. 2016.

CUNHA, Maria Isabel da. Pesquisa e docência: cenários e impasses epistemológicos para a qualificação do ensino superior. Revista Docência Universitária - REDU. Espanha, s.d. (no prelo).

DAY, Christopher. Desenvolvimento profissional de professores: os desafios da aprendizagem permanente. Portugal: Porto, 2001.

ESTEVES, Manuela. A investigação como estratégia de formação de professores: perspectivas e realidades. Lisboa, 2001. Disponível em: <http://www4.crb.ucp.pt/Biblioteca/Mathesis/Mat10/mathesis10_217.pdf>. Acesso em: 20 abr. 2016.

FREIRE, Paulo. Pedagogia da autonomia. Rio de Janeiro: Paz e Terra, 1996.

GARCÍA GÓMEZ, Soledad. El desarrollo profesional análisis de un concepto complejo. Revista de Educación, Madrid, n. 318, p. 175-187, 1999.

GONÇALVES, Maria de Cássia Passos Brandão; FREIRE, Inês Angélica. A instituição educativa como o lócus da formação inicial e permanente de professores. In: LEITE, Carlinda; ZABALZA, Miguel (Coords.). Ensino superior: inovação e qualidade na docência. Porto: Centro de Investigação e Intervenção Educativas - CIIE, 2012.

LIZARRAGA, Maria Luisa Sanz de Acedo. Competencias cognitivas em educacion superior. Madrid: Narcea Ediciones, 2010.

PAOLI, J. Niuvenius. O princípio da indissociablidade do ensino e da pesquisa: elementos para uma discussão. Cadernos CEDES - Educação superior: autonomia, pesquisa, extensão, ensino e qualidade, São Paulo, n.22, 1988. 
POZO, Juan Ignacio; PÉREZ, Echeverría M. del Puy (Coords.). Psicología del aprendizaje universitario: la formación en competências. Madrid: Morata, 2009.

RELATÓRIO GERAL DA EJA - Pedagogia. Departamento de Ciências Humanas e Letras. Campus de Jequié: Universidade Estadual do Sudoeste, 2015.1.

SACRISTÁN, José Gimeno. Consciência e acção sobre a prática como libertação profissional dos professores. In: NÓVOA, Antonio (Org.). Profissão professor Portugal: Porto, 1999.

STRECK, Danilo R.; REDIN, Euclides; ZIRTKOSKI, Jaime José (Orgs.). Dicionário Paulo Freire. Belo Horizonte: Autêntica, 2008.

SOARES, Sandra Regina. A pesquisa como eixo da prática educativa na formação de professores na universidade: desafios e possibilidades. Anais do XVI ENDIPE - Encontro Nacional de Didática e Práticas de Ensino - UNICAMP, Campinas, 2012.

A pesquisa como norteadora da formação profissional na universidade. Estudos em Avaliação Educacional, São Paulo, v. 24, n. 55, p. 224-245, abr./ago. 2013a. Disponível em: <http://www.fcc.org.br/pesquisa/publicacoes/eae/arquivos/1819/1819.pdf.>Acesso em: 26 abr. 2016.

. A pesquisa como princípio formativo: experiência em uma disciplina na pós-graduação.

Série Práxis e Docência Universitária, volume II. Salvador: Eduneb, 2013 b.

. Relação entre ensino, pesquisa e desenvolvimento profissional docente: potencialidades e constrangimentos numa universidade portuguesa. In: CUNHA, Maria Isabel; LUCARELLI, Elisa (Orgs.). Estratégias de qualificação do ensino e o assessoramento pedagógico. Reconhecendo experiências em universidades Ibero-Americanas. Criciúma: UNESC, 2014.

TRILLO, Felipe. Atitudes dos estudantes: um indicador da qualidade universitária. In: (Org.). Atitudes e valores no ensino. Lisboa: Instituto Piaget, 2000.

ZABALA, Antoni; ARNAU, Laia. Como aprende e ensinar competências. Porto Alegre: Artmed, 2010.

Data de recebimento: $25 / 09 / 2016$

Data de aceite: $23 / 05 / 2017$

\section{Sobre as autoras:}

Luziêt Maria Fontenele-Gomes é Mestre em Letras: Cultura, Educação e Linguagens, pela Universidade Estadual do Sudoeste da Bahia; graduação em Letras, pela Faculdade de Filosofia Ciências e Letras de Cabo Frio; Especialização em Problemas do Desempenho Escolar, pela Faculdade de Humanidades D. Pedro II, do Rio de Janeiro. Professora Assistente do Departamento de Ciências Humanas e Letras, da Universidade Estadual do Sudoeste da Bahia (1995); Coordenadora do Núcleo de Educação de Jovens e Adultos (NEPEJA); Coordenadora do Subprojeto Interdisciplinar do Programa Institucional de Bolsas de Iniciação à Docência com Linha de Ação em Educação de Jovens e Adultos, em convênio com a Comissão de Aperfeiçoamento de Pessoal de Nível Superior (PIBID UESB/CAPES). Atua 
nas áreas de Linguagem, Leitura, Linguística Aplicada e tem experiência na área de Educação de Jovens e Adultos em situação de privação de liberdade. Endereço Eletrônico: luzietfontenele@gmail.com

Maria de Cássia Passos Brandão Gonçalves é Mestre em Educação, pela Universidade Federal da Bahia; graduação em Pedagogia, pela Faculdade de Educação da Bahia; Especialização em Alfabetização, pela Faculdade de Educação da Bahia. Professora Assistente do Departamento de Ciências Humanas e Letras, da Universidade Estadual do Sudoeste da Bahia (2001); Membro do Grupo de Pesquisa Docência Universitária e Formação de Professores - DUFOP. Atua nas áreas de Educação de Jovens e Adultos e Formação de Professores. Endereço Eletrônico: cassiauesb@gmail.com 